\title{
Incidencia de COVID-19 en la inscripción de estudiantes a los programas de educación superior
}

\section{Incidence of COVID-19 in the registration of students to higher education programs}

\author{
RINCON, Isbelia K. ${ }^{1}$ \\ SUAREZ, Sir A. ${ }^{2}$ \\ SUAREZ CASTRILLON, Albert M. ${ }^{3}$
}

\begin{abstract}
Resumen
La investigación muestra la incidencia del COVID-19 como factor determinante en la intención de iniciar un programa de educación superior. Los datos de estudio fueron recolectados en la Provincia de Ocaña antes y durante la pandemia, reflejando una reducción del número de aspirantes cercana al $50,9 \%$, con más impacto en los programas de jornada diurna. Se evidencia que los programas de ayuda estudiantil no mitigan por completo las deficiencias económicas para contrarrestar la disminución de nuevos estudiantes.

Palabras clave: inscripción estudiantil, COVID-19, educación superior, matrícula académica.

Abstract

Research shows the incidence of COVID-19 as a determining factor in the intention to start a higher education program. The study data were collected in the Province of Ocaña before and during the pandemic, reflecting a reduction in the number of applicants close to $50.9 \%$, and increasing the impact on daytime programs. It is evident that the student aid programs do not completely mitigate the financial deficiencies to offset the decrease in new students.

key words: student registration, COVID-19, higher education, academic enrollment.
\end{abstract}

\section{Introducción}

Según una nota de presa, un miembro de la Organización Panamericana de la Salud (OPS) manifestó que el virus del COVID-19 seguirá propagándose, incluso si se contará con una vacuna (AFP, 2020). Los datos no son alentadores para América Latina reportando los mayores índices de nuevas muertes en todo el mundo para el mes de septiembre de 2020 y ubicando a Brasil con el 19\% del total de muertes (OPS, 2020), mientras Colombia cuenta que con 32 departamentos y sus fronteras limitan con Perú, Brasil, Venezuela, Ecuador y Panamá, se ubica como el segundo país con más contagios en Sur América, teniendo 902.747 casos confirmados, 783.131 recuperados y 27.660 fallecidos (INS, 2020).

Con las cifras en aumento, el gobierno colombiano ha tomado medidas que intentan contener la propagación de la enfermedad, las cuales incluyen protocolos como la declaración de emergencia nacional decretada por la

\footnotetext{
${ }^{1}$ Docente. Programa Ingenieria de Sistemas. Universidad Francisco de Paula Santander Ocaña. Grupo de Investigación Grucite. ikrinconp@ufpso.edu.co 2 Docente. Programa Ingenieria de Sistemas. Universidad Francisco de Paula Santander Ocaña. Grupo de Investigación Grucite. sasuarezc@ufpso.edu.co ${ }^{3}$ Docente. Programa Ingenieria Mecanica. Universidad de Pamplona. Grupo de Investigación Gimup. albertmiyer@unipamplona.edu.co
} 
Presidencia de la República (2020), la emergencia sanitaria por el Ministerio de Salud (Minsalud, 2020a) y los lineamientos para enfrentar el COVID-19 (Minsalud, 2020b). En materia de educación se han decretado medidas para la prevención mediante el sistema de alternancia y quédate en casa (Mineducación, 2020a), y en ayudas económicas se presentaron medidas con créditos especiales para los estratos más vulnerables (Mineducación, 2020b).

A lo anterior se le agregan los programas ya existentes como Jóvenes en Acción adscripto al Departamento de Prosperidad Social (DPS, 2020), el cual entrega transferencias monetarias condicionadas con la finalidad de que puedan continuar su estudios de educación superior, bajo condiciones que deben cumplir los aspirantes para permanecer en el programa, como estar admitido en la institución. En 2018, se creó el Programa de Generación E el cual otorga el beneficio de matrícula desde el comienzo de la carrera universitaria (Mineducación, 2018), dirigido al desarrollo y transformación de las regiones con un ingreso gratuito para los beneficiarios. Norte de Santander forma parte de los 32 departamentos de Colombia y siguiendo las mismas directrices nacionales, la Gobernación del Norte de Santander (2020) implementó el programa de subsidios a estudiantes de las universidad públicas del departamento: Universidad de Pamplona, Universidad Francisco de Paula Santander sede Cúcuta y Ocaña (UFPSO), Instituto Superior de Educación Rural (ISER) y la Unidad Tecnológica de Santander, otorgando 25 mil subsidios de matrícula. En materia de Contagios las cifras siguen aumentando con 17.577 para principios de octubre, razón por la cual la UFPSO implementó estrategias en materia educativa y de prevención (UFPSO, 2020).

La deserción y las matriculas en las Universidades siguen empeorando en los últimos años en Colombia (ASCUN, 2020), los cuales motivan a realizar diversas investigaciones en las universidades para conocer los factores que inciden directamente. Es el caso del estudio realizado en la Fundación Católica del Norte (Núñez, 2011) donde concluyen que los factores externos apuntan a las condiciones socioeconómicas, al acceso a las tecnologías, a la calidad académica con que inician su formación y al poco interés por una educación virtual, y proponen que la educación virtual debe crear sus propios modelos. Mientras en la Escuela de Microbiología de la Universidad de Antioquía se analiza la deserción desde la perspectiva del estudiante (Hincapié, Hernández, Arteaga, Delgado, y Pérez, 2012) y sus conclusiones más interesantes determinaron que no existía una relación deteriorada entre docente-estudiante. En el estudio realizado en la Universidad Nacional encontraron como factor importante el desempleo juvenil, debido a la necesidad de buscar una manera para gestionar los costos académicos (Bermúdez Pedraza et al., 2019).

Al no ser homogénea la deserción por áreas del conocimiento, se encuentran trabajos específicos por facultades como el de la UPTC que hace un análisis de la facultad de ingeniería (Higuera Martinez, 2017) concluyendo que se debe establecer un proceso de seguimiento a cada estudiante al inicio del programa, ya que la universidad cuenta con procesos sólidos para evitar la deserción, mientras que en la Universidad Santiago de Cali (Stephany, 2019), se investigaron los factores de deserción en enfermería incluyendo factores individuales y familiares, los cuales se unen a los socioeconómicos, con una tasa de deserción del 16\%. Varios trabajos ya se habían adelantado al uso de herramientas tecnológicas (Ramírez Saavedra, Sarmiento, y Millán Rojas, 2016) analizando la implementación de las plataformas TIC y B-learning para el uso de tutorías como propuesta de deserción. Todos los trabajos relacionados con deserción han tenido un cambio de 360 grados por el COVID-19, donde los factores anteriores de deserción se han intensificado aún más, y las universidades pronostican una baja sensible en sus matrículas, donde las becas y programas de apoyo por parte de las instituciones intentan mitigar este problema.

Si el COVID-19 ya es un problema fuera de control para estudiantes antiguos y universidades, ahora se convirtió en un factor importane para el futuro de nuevos aspirantes. Es por eso que el objetivo de este trabajo es analizar la incidencia de la pandemia en los indicadores de aspirantes nuevos a la universidad, los cuales reflejan los 
problemas actuales de los núcleos familiares en Colombia, inclusive al optar por una carrera en una universidad pública. El estudio es tomado de los indicadores de inscripción de la UFPSO, universidad pública ubicada en la Provincia de Ocaña y con estratos sociales ubicados en 1 y 2 en su mayoría, llegando a porcentajes del $97 \%$, y ubicada cerca a zonas de conflicto armado que disminuyen las oportunidades de ingresar a la vida universitaria. La investigación se centra en los indicadores antes del COVID-19 y en pleno aislamiento para ingresar a un nuevo semestre en la universidad.

\section{Metodología}

La metodología usada en el estudio es descriptiva y con una observación cuantitativa. Los datos fueron obtenidos del Sistema de Información (SIA) de la UFPSO en el proceso de Admisiones, Registro y Control. También se describió secuencialmente el proceso de inscripción implementado de forma online disponible para todos los aspirante independiente de su ubicación, el cual consta de 4 pasos principales (Preinscripción, Inscripción, Liquidación/matricula y Segunda Opción), y su facilidad o inconveniente en el proceso de inscripción.

Figura 1

Boletín Epidemiológico Norte de Santander

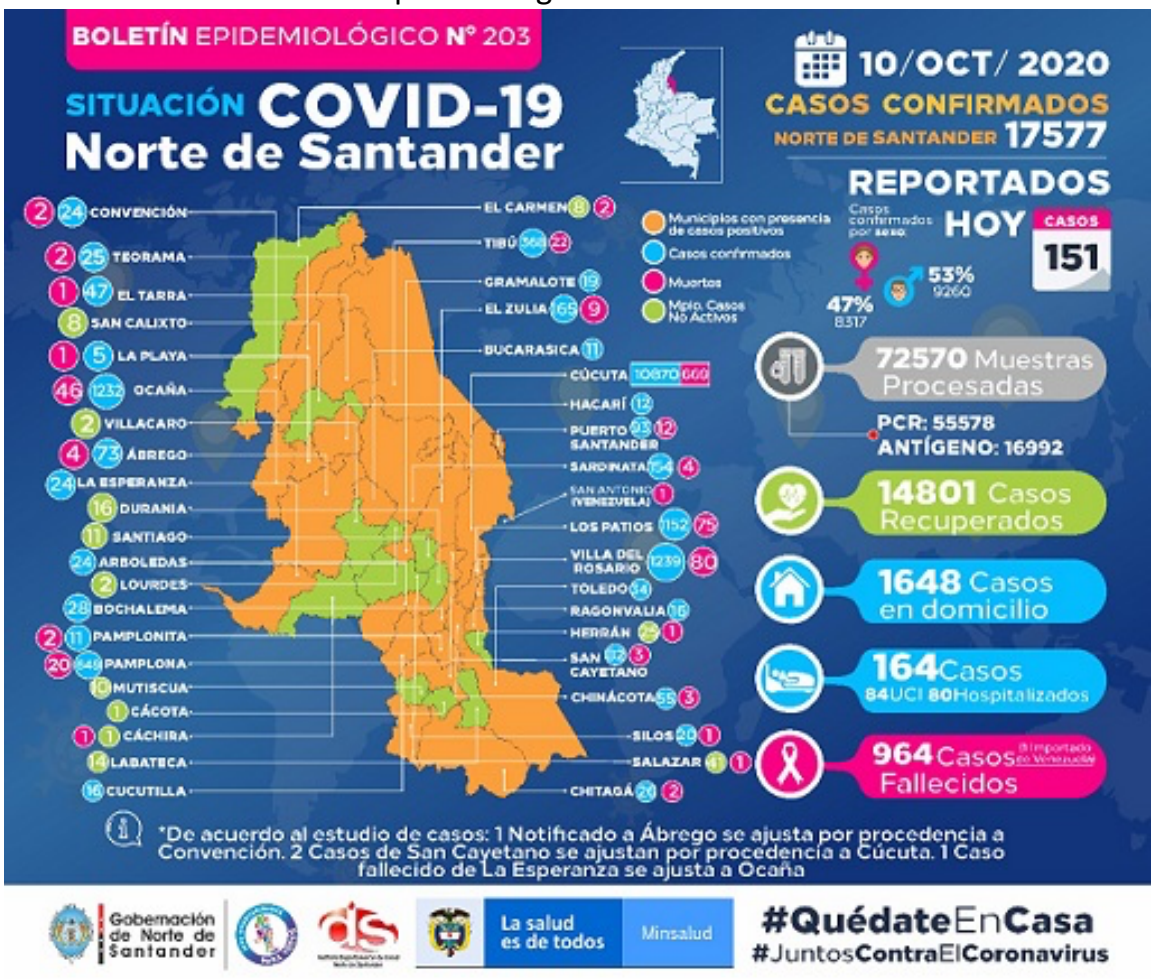

Fuente: Minsalud, 2020c

El contagio de COVID en la región del Catatumbo continua aumentando, según reportes del Ministerio de Salud y la gobernación del Norte de Santander. La Figura 1, muestra los diferentes municipios con sus estadísticas actualizadas, donde Ocaña presenta 46 muertos y 232 contagios (Minsalud, 2020c), y sumados a toda la provincia hace permanecer a la UFPSO con protocolos de alternancia sin iniciar labores presenciales. Tomando como medida para continuar con las clases y ofrecer el segundo semestre de 2020, se implementaron todos los cursos académicos virtualizados en un $100 \%$, no obstante no es una razón suficiente para determinar si los aspirantes a ingresar a una carrera en la institución lo puedan hacer. Por eso la muestra se tomó en base a sus cuatro facultades: Ciencias Administrativas y Económicas (Contaduría Nocturna, Contaduría Diurna, Administración de Empresas), Ciencias Agrarias y del Ambiente (Ingeniería Ambiental y Zootenía), Ingeniería (Civil, Mecánica, Sistemas) y Educación (Comunicación Social, Derecho día, Derecho Nocturno). La muestra se toma en base a los 
estudiantes preinscritos e inscriptos antes de la pandemia con fecha del semestre 2019-2 que iniciaron en el 2020-1, y los mismos datos pero durante la pandemia para iniciar en el segundo semestre de 2020. Se analizan cuatro indicadores: preinscripción, PIN, Inscripción y entrega, donde la preinscripción muestra la intención de ingresar a una carrera universitaria y la entrega muestra si finalizó el proceso de forma exitosa para poder ingresar a un programa. La metodología es descriptiva y con una observación cuantitativa.

\section{Resultados}

El análisis de los datos de preinscripción e inscripción, antes y durante la pandemia puede reflejar los indicadores suficientes para tomar medidas adecuadas para los siguientes semestres, donde el COVID-19 seguirá presente en la mayoría de países y principalmente en la región.

\subsection{Proceso de preinscripción e inscripción}

La UFPSO cuenta con un proceso completamente en línea desde antes de la pandemia, razón por la cual ningún aspirante debía dirigirse físicamente a la universidad para realizar sus trámites. En la figura 2, se muestra la presentación de la página de inscripciones del proceso de Admisiones, Registro y Control, con los pasos a diligenciar cada estudiante. Al ser un proceso totalmente en línea no hubo necesidad de implementar nuevos procedimientos y se mantiene un acceso fácil para estudiantes durante el COVID-19, logrando el aspirante su inscripción desde cual lugar de ubicación. Los cuatro pasos son: Preinscripción, Inscripción, Admitido/Liquidación y Segunda Opción.

Figura 2

Pasos en línea para el proceso de admisión a la UFPSO

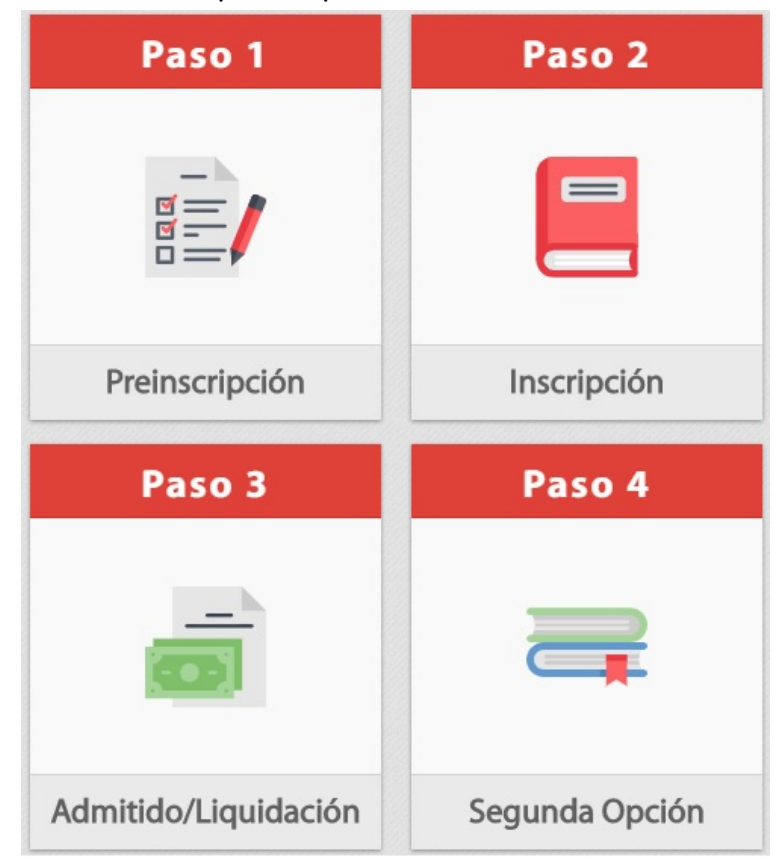

Fuente: elaboración propia - División de Sistemas

El proceso de preinscripción obtiene los datos básicos del aspirante, con la finalidad de generar un volante de pago por conceptos de inscripción, por lo tanto el estudiante deberá pagar el valor del formulario de registro y posteriormente se le genera un PIN, el cual le permitirá seguir al segundo paso de Inscripción. El proceso de inscripción se modeliza en la Figura 3, incluyendo los pasos de admitido y matricula. 
Figura 3

Pasos de inscripción

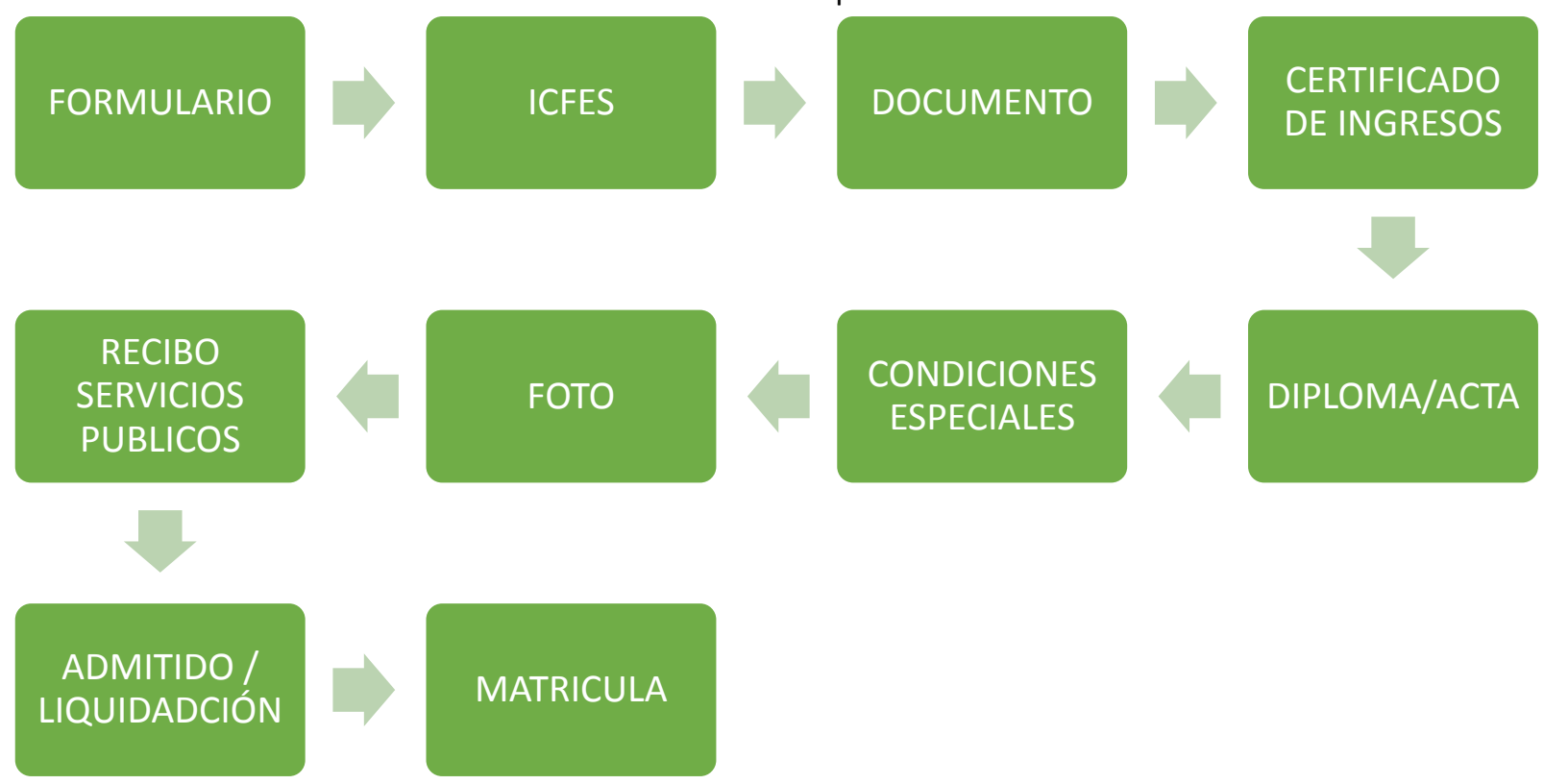

Fuente: elaboración propia

Cada uno de los pasos necesarios para su selección deben ser diligenciados, se deben de subir archivos pdf para ser revisados, prestando énfasis en las pruebas del ICFES las cuales se constatan con la base de datos de la entidad y las de condiciones especiales mediante el Ministerio del Interior, con la debida verificación del aspirante. El proceso es cada vez más ágil, brindando una solución oportuna para poder ingresar a la Universidad. Y los únicos inconvenientes es la falta por parte del aspirante al no leer las sugerencias y manuales dispuestos por la UFPSO para diligenciarlo de forma exitosa.

\subsection{Relación entre preinscripción e inscripción antes y durante el COVID-19}

Al diligenciar la preinscripción y continuar con el proceso de inscripción, se detecta la intención del estudiante como factor para estudiar una carrera, y se tienen cuatro etapas para llegar a un proceso exitoso: preinscripción, PIN, inscripción y Entrega. Donde la preinscripción mide la intención de ingreso; PIN es la compra del formulario, inscripción es hacer efectiva la intención y Entrega es finalmente el compromiso de seguir con su intención de acceder a la universidad. Para efectos de inscripción final se tomarán los que entreguen como verdaderos inscriptos. En el cuadro 1, el porcentaje de deserción a la inscripción en Contaduría Diurna es de un 74.38\%, Contaduría Nocturna 62.72\%, Tecnología 65.75\% y Administración 65.17\%; reflejando que la intención inicial de preinscripción se mantiene en valores muy bajos en los cuatro programas de la Facultad de Administración.

Cuadro 1

Facultad de Administración - datos de

ingreso 2019-1 y 2020-1 COVID-19

\begin{tabular}{|c|c|c|c|c|c|c|c|c|}
\hline PROGRAMAS & \multicolumn{3}{|c|}{$2019-1$ ingreso 2020-1 } & \multicolumn{4}{|c|}{$2020-1$ COVID-19 ingreso 2020-2 } \\
\hline Contaduría pública diurna & Pre & PIN & Ins & Entrega & Pre & PIN & Ins & Entrega \\
\hline Contaduría pública nocturna & 121 & 95 & 90 & 90 & 50 & 33 & 38 & 38 \\
\hline Tec. Gestión Comercial y financiera & 110 & 76 & 70 & 69 & 34 & 19 & 33 & 33 \\
\hline Administración de Empresas & 201 & 138 & 134 & 131 & 90 & 73 & 66 & 45 \\
\hline
\end{tabular}

Fuente: elaboración propia 
Los datos que se recogen durante la pandemia en el periodo 2020-1 para iniciar clases en el periodo 2020-2 muestran un efecto a la baja en todas las carreras, llegando incluso a valores donde no alcanzan a cubrir la oferta de la universidad. En el gráfico 1, se observa la desaceleración en la intención de aspirantes a ingresar a la universidad con rangos de más del $100 \%$. Sin embargo se mantiene estable las carreras tecnológicas al momento de terminar todo el proceso de inscripción.

\section{Gráfico 1}

Ciencias Administrativas y Económicas

inscripciones antes y durante el COVID-19

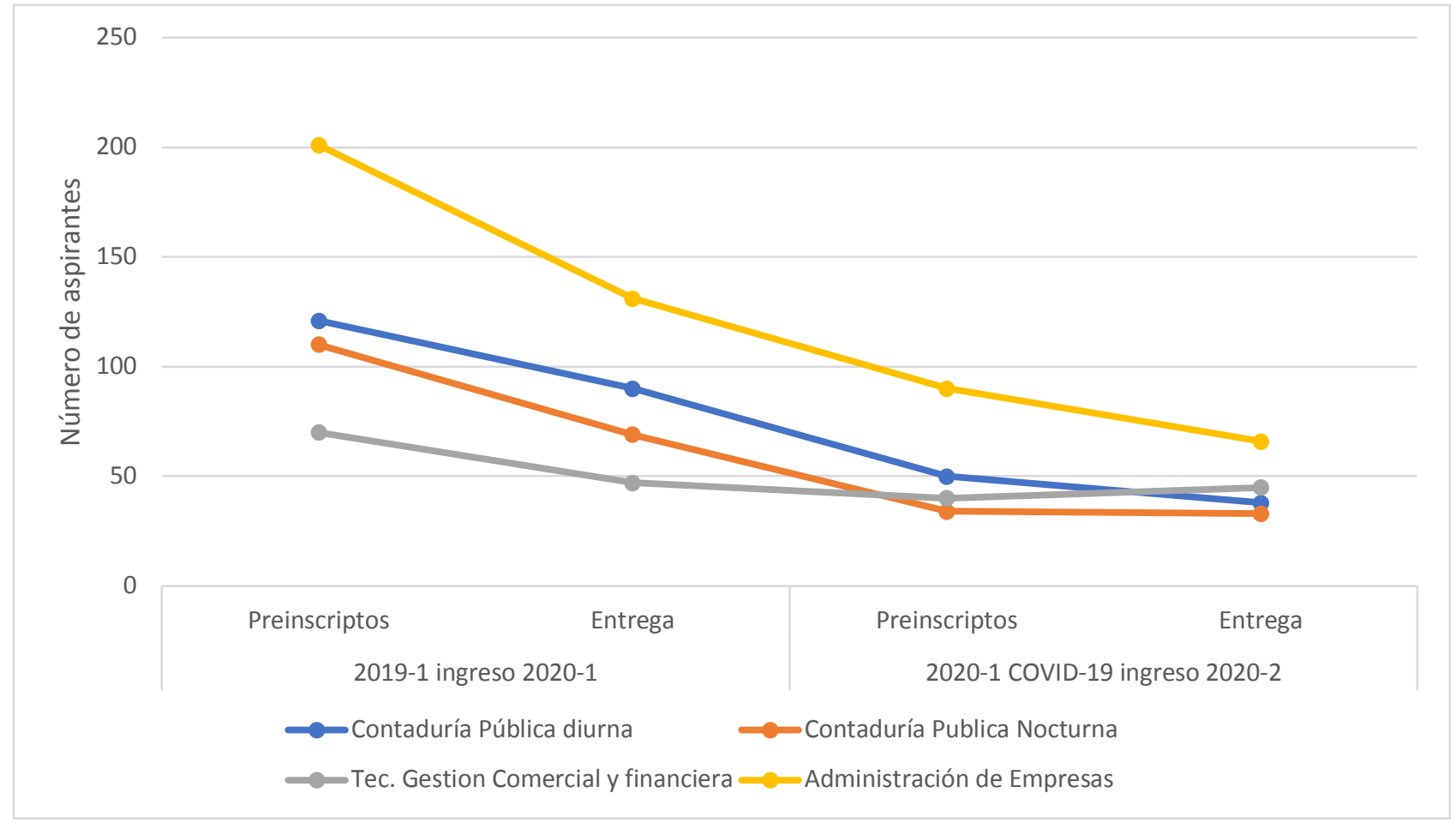

Fuente: elaboración propia

Los resultados de la Facultad de Ciencias Agrarias siguen mostrando descenso en la intención hasta del $20 \%$ en la época del COVID-19; aunque la tendencia a no terminar es del 33\% antes del virus. Los datos reflejan una disminución de inscriptos del $46.84 \%$ en ingeniería ambiental y $57.89 \%$ en zootecnia (ver cuadro 2 ).

Cuadro 2

Facultad Ciencias Agrarias - datos de ingreso 2019-1 y 2020-1 COVID-19

\begin{tabular}{|c|c|c|c|c|c|c|c|c|}
\hline \multirow{2}{*}{ Programas } & \multicolumn{4}{|c|}{$2019-1$ ingreso 2020-1 } & \multicolumn{4}{c|}{$2020-1$ COVID-19 ingreso 2020-2 } \\
\cline { 2 - 10 } & Pre & PIN & Ins & Entrega & Pre & PIN & Ins & Entrega \\
\hline Ingeniería Ambiental & 166 & 120 & 111 & 111 & 65 & 52 & 53 & 52 \\
\hline Zootecnia & 113 & 76 & 76 & 76 & 55 & 42 & 44 & 44 \\
\hline
\end{tabular}

Fuente: elaboración propia

En el gráfico 2, se pueden ver que los datos se mantienen a la baja, con una disminución enorme en la carrera de ingeniería ambiental, donde las prácticas tienen una tendencia a ser más presenciales, y el descenso de aspirantes en la facultad es de $\mathbf{5 2 . 3 7 \%}$. 
Gráfico 2

Ciencias Agrarias inscripciones antes y durante el COVID-19

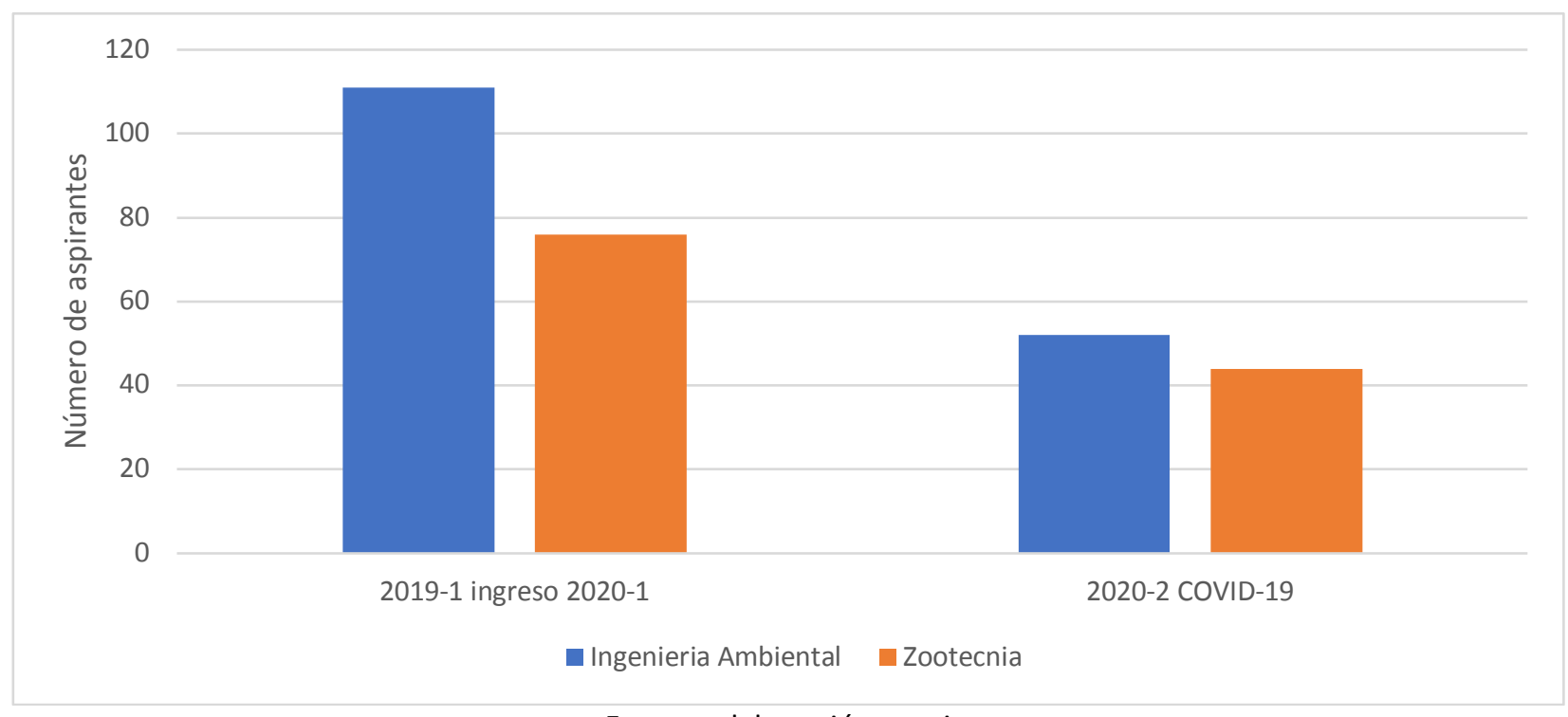

Fuente: elaboración propia

La facultad de Ingeniería cuenta con los programas: Civil, Mecánica y Sistemas. El programa de ingeniería civil es uno de los más solicitados en la UFPSO y su descenso marca cifras del $41.55 \%$ en la inscripción, inclusive después de la preinscripción el estudiante desiste de seguir el proceso en un $64.53 \%$, mientras que los programas de ingeniería Mecánica y Sistemas, mantienen su intención después de la preinscripción, pero igual bajan al compararlos con datos antes de la pandemia (ver gráfico 3). Llama la atención que la carrera de ingeniería de Sistemas la cual cuenta con áreas tecnológicas dedicadas a la virtualidad en la mayoría de las asignaturas y con un $100 \%$ de los programas ya virtualizados no mantenga una tendencia positiva, bajando en un $44.61 \%$ en la intención del aspirante, lo que permite concluir que la modalidad no el obstáculo para acceder a una carrera universitaria.

\section{Gráfico 3}

Facultad de Ingeniería inscripciones antes y durante el COVID-19

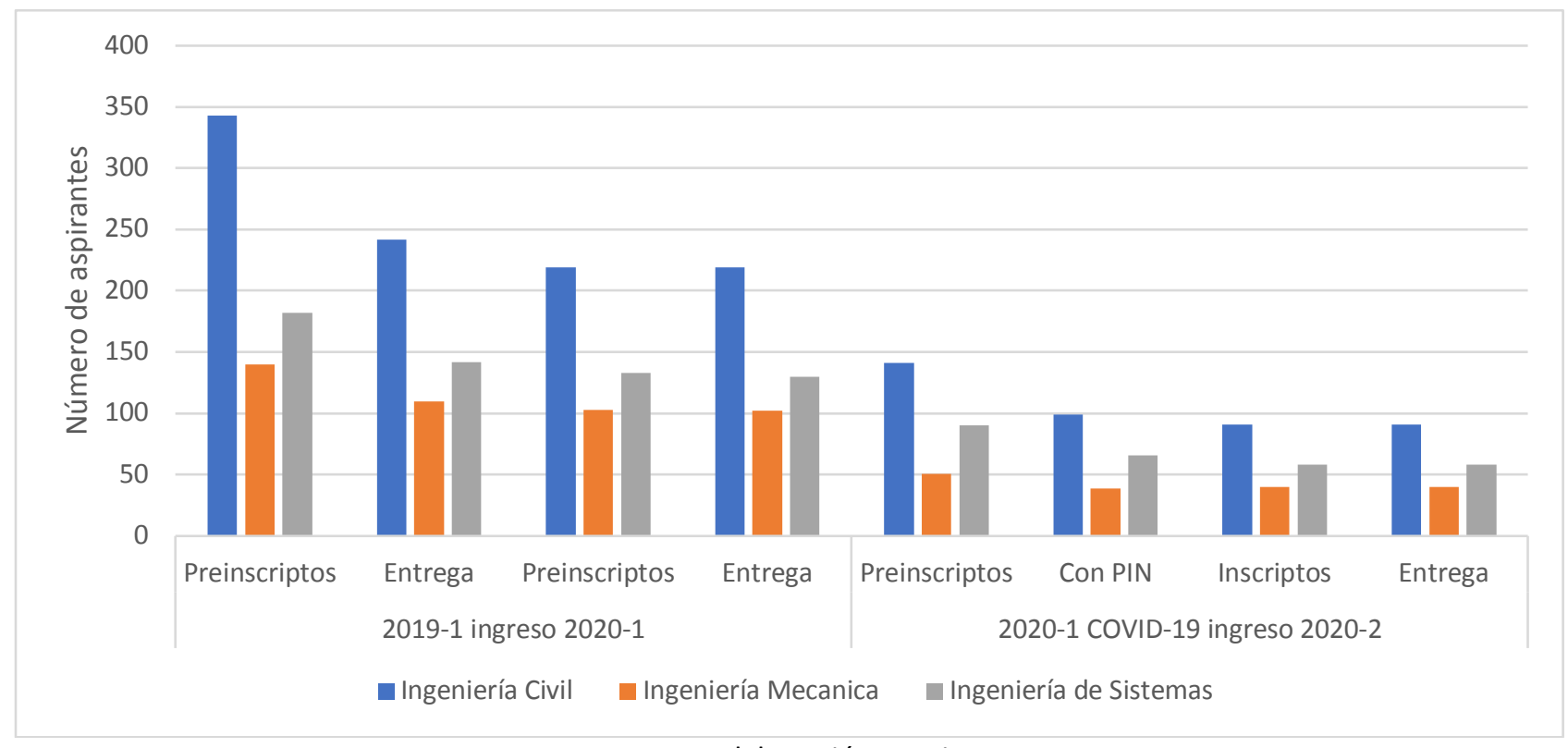

Fuente: elaboración propia 
La facultad de Educación Artes y Humanidades cuenta con tres carreras: Derecho diurno y nocturno, y la carrera de comunicación social. El cuadro 3, permite ver que el programa de Derecho diurno tiene una intención baja entre sus aspirantes viéndose afectado por el COVID-19, algo que no se observa en Derecho nocturno, siendo este último programa el único que presenta una tendencia de crecimiento del 126\% (ver gráfico 4), el cual puede deberse por el factor de la jornada y la preparación para seguir clases virtuales que pueden complementar con sus largas jornadas de trabajo; mientras que la carrera de Comunicación social mantiene la tendencia de los otros programas con un $44.85 \%$ en intención de inscripción.

Cuadro 3

Facultad de Educación - datos de ingreso antes y durante el COVID-19

\begin{tabular}{|c|c|c|c|c|c|c|c|c|}
\hline \multirow{2}{*}{ Programas } & \multicolumn{4}{|c|}{$2019-1$ ingreso 2020-1 } & \multicolumn{3}{c|}{$2020-1$ COVID-19 ingreso 2020-2 } \\
\cline { 2 - 10 } & Pre & PIN & Ins & Entrega & Pre & PIN & Ins & Entrega \\
\hline Derecho Diurno & 373 & 260 & 235 & 234 & 165 & 120 & 98 & 97 \\
\hline Derecho Nocturno & 58 & 42 & 34 & 34 & 124 & 89 & 77 & 77 \\
\hline Comunicación Social & 200 & 142 & 136 & 136 & 82 & 64 & 62 & 61 \\
\hline
\end{tabular}

Gráfico 4

Relación de preinscriptos y entrega Facultad de Educación

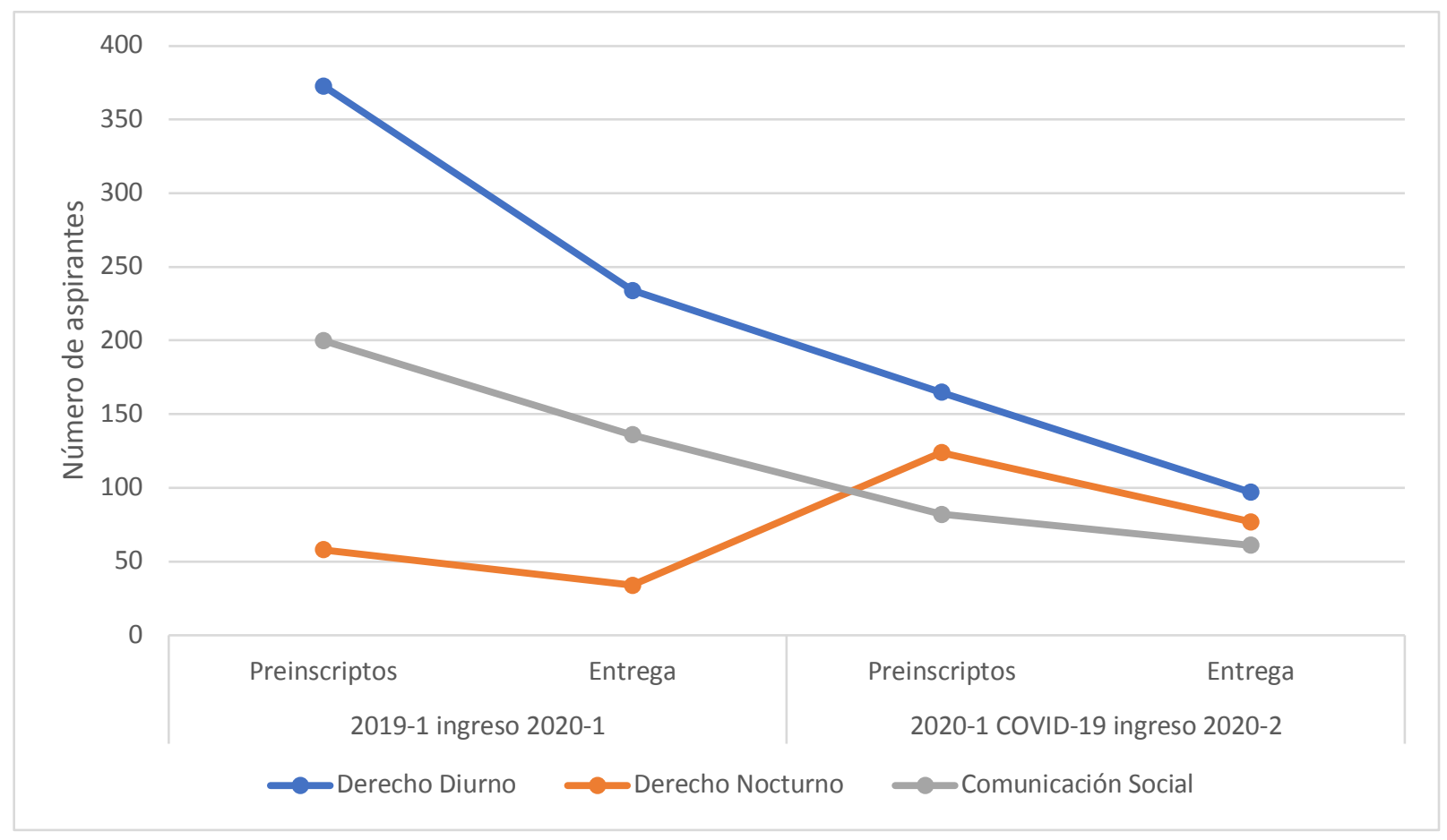

Fuente: elaboración propia

\subsection{Efectos del COVID-19 en la inscripción de aspirantes nuevos}

EL COVID.-19 ha incrementado los problemas ya existentes en los diferentes ciclos de educación superior, donde la UFPSO no escapa al descenso en la intención de ingresar a una carrera universitaria. Al analizar dos variables: primero la intención dada en la preinscripción y la finalización del proceso como un hecho, se determina que en las cuatro facultades el deterioro ha sido bastante alto, si se tiene en cuenta que ya el gobierno Nacional y Departamental implementaron diversos programas para el acceso a la educación superior. En el gráfico 5 se 
muestra la disminución en la intención de preinscripción de un $47.52 \%$ y del $50.90 \%$ en la inscripción final a la universidad, afectando en mayor medida a los programas de la Facultad de Ciencias Agrarias y del Ambiente, la cual ya tenían signos de una baja en la intención de selección antes del COVID-19. la Facultad de Ingeniería es la que más ha sentido el efecto del COVID-19 inscribiéndose tan solo el $41.9 \%$ comparadolo con los datos antes de la pandemia, mientras que la facultad de artes y humanidades presenta el mayor índice de inscripción con un $58.16 \%$, pero con más del $40 \%$ de perdida en la cantidad de aspirantes.

La disminución del porcentaje de inscripción en la UFPSO en sus cuatro facultades ronda el 50.90\%, un dato nada alentador, pues incide sobre la cantidad de cursos y docentes que pueden desempeñarse, afectando la económica de la región.

\section{Gráfico 5}

Relación de inscriptos en las facultades de la UFPSO durante el COVID-19

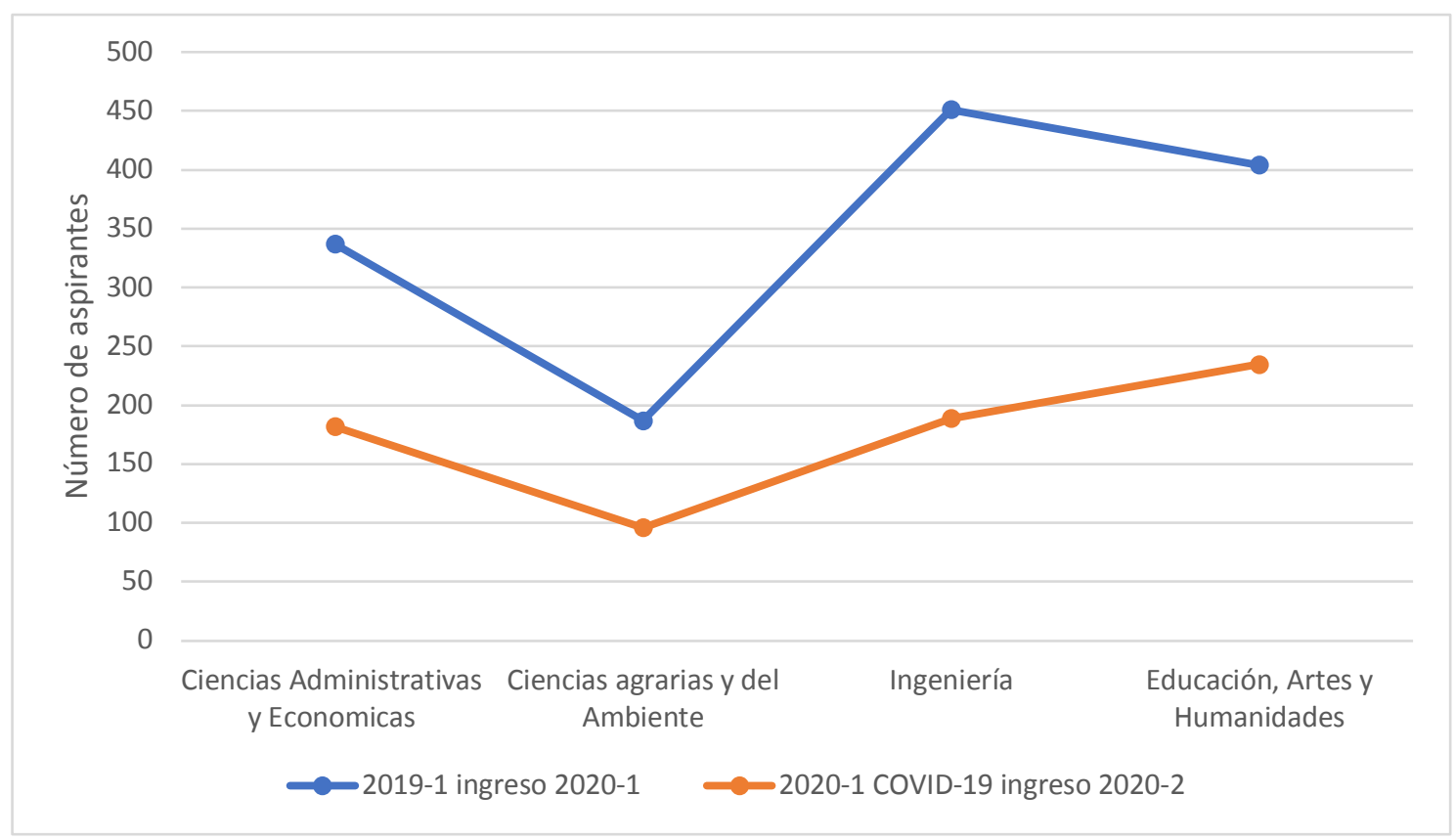

Fuente: elaboración propia

\section{Conclusiones}

Se evidenció que la UFPSO, ha tenido una disminución notable en la inscripción de estudiantes nuevos en todos los programas académicos debido al COVID-19. Los programas nocturnos muestran una tendencia a mantenerse con un gran número de solicitudes de ingreso, mientras que las áreas de ingeniería Ambiental y Zootecnia se mantienen en una reducción constante que ya venía desde antes del virus. Los programas de ayuda decretados para mitigar los problemas económicos del COVID-19 en materia de educación, no muestran ser una herramienta motivadora para la mayoría de aspirantes, quienes en la etapa de preregistro tienen una intención que finalmente no plasman en el registro final. El procedimiento de inscripción en línea y la virtualización de las clases se convierten en factores para una interacción adecuada con el aspirante, dando la oportunidad de incorporarse sin tener que pensar en los inconvenientes de la metodología de alternancia.

\section{Referencias bibliográficas}

Agencia France Press (AFP), (2020, septiembre). Covid-19 seguirá propagándose incluso con una vacuna, advierte la OPS | El Economista. Recuperado 11 de octubre de 2020, de 
https://www.eleconomista.com.mx/arteseideas/Covid-19-seguira-propagandose-incluso-con-una-vacunaadvierte-la-OPS-20200923-0095.html

ASCUN. (2020). Análisis breve de cifras de educación superior en Colombia | Asociación Colombiana de Universidades. Recuperado 10 de octubre de 2020, de https://www.ascun.org.co/noticias/detalle/analisisbreve-de-cifras-de-educacion-superior-en-colombia

Bermúdez Pedraza, M., Camelo Plazas, J., García Mazo, S., Garzón Franco, D., Mediorreal Gutiérrez, F., y Torres Clavijo, J. (2019). El desempleo juvenil y la deserción en la Universidad Nacional, sede Bogotá. Papeles, 10, 53-66.

DPS. (2020, abril). Manual operativo Programa Jovenes en Acción. Recuperado de http://centrodedocumentacion.prosperidadsocial.gov.co/2020/JeA/M-GI-TM-1-MANUAL-OPERATIVOJOVENES-EN-ACCION-V8-ABRIL.PDF

Gobernación Norte de Santander. (2020, junio 10). Estudiantes de universidades públicas accederán a 25 mil subsidios para su matrícula académica-Noticias Gobernación Norte de Santander. Recuperado 11 de octubre de 2020, de http://www.nortedesantander.gov.co/Noticias-Gobernaci\%C3\%B3n-Norte-deSantander/ArticleID/17589/Estudiantes-de-universidades-p\%C3\%BAblicas-acceder\%C3\%A1n-a-25-milsubsidios-para-su-matr\%C3\%ADcula-acad\%C3\%A9mica

Higuera Martinez, O. (2017). Deserción estudiantil en Colombia y los programas de ingeniería de la Uptc seccional Sogamoso. Ingeniería Investigación y Desarrollo, 17. https://doi.org/10.19053/1900771X.v17.n1.2017.5593

Hincapié, F. A., Hernández, A. W., Arteaga, J. S., Delgado, C. M. M., y Pérez, R. D. S. (2012). La deserción universitaria desde la perspectiva del estudiante. Informe de casos: Programa Microbiología y Bioanálisis. Praxis, 8(1), 17-38.

INS. (2020, octubre). Reporte de Coronavirus Colombia. Recuperado 11 de octubre de 2020, de https://www.ins.gov.co/Noticias/paginas/coronavirus.aspx

Mineducación. (2018, octubre). Gobierno lanzó 'Generación E', el nuevo programa de educación superior que beneficiará a 336 mil estudiantes de todo el país durante el cuatrienio-Ministerio de Educación Nacional de Colombia. Recuperado 10 de octubre de 2020, de https://www.mineducacion.gov.co/1759/w3-article377779.html?_noredirect=1

Mineducación. (2020a). Lineamientos para la prestación del servicio de educación en casa y en presencialidad bajo el esquema de alternancia y la implementación de prácticas de bioseguridad en la comunidad educativa. Ministerio de Educación. Recuperado de Ministerio de Educación website: https://www.mineducacion.gov.co/1759/articles-399094_recurso_1.pdf

Mineducación. (2020b, mayo). Nuevas medidas de apoyo al sector educativo anunció hoy el Gobierno Nacional-Ministerio de Educación Nacional de Colombia. Recuperado 10 de octubre de 2020, de https://www.mineducacion.gov.co/1759/w3-article-397798.html?_noredirect=1

Minsalud. (2020a). Directiva 02 de 2020 Por la cual se declara la emergica sanitaria por causa del coronavirus COVID-19 y se adoptan medidas para hacer frente al virus. Recuperado de https://coronaviruscolombia.gov.co/Covid19/docs/decretos/minsalud/resolucion_385_de_2020_minsalud .pdf 
Minsalud. (2020b). Lineamientos, Orientaciones y Protocolos para enfrentar la COVID-19 en Colombia.

Ministerio de Salud de Colombia. Recuperado de Ministerio de Salud de Colombia website:

https://www.minsalud.gov.co/sites/rid/Lists/BibliotecaDigital/RIDE/VS/lineamientos-orientacionesprotocolos-covid19-compressed.pdf

Minsalud. (2020c, octubre). Brote de coronavirus casos en el departamento Norte de Santander. Recuperado 11 de octubre de 2020, de Gobernación de Norte de Santander website:

http://www.nortedesantander.gov.co/Noticias-Gobernación-Norte-de-Santander/ArticlelD/18182/Brotede-coronavirus-aumentó-a-151-casos-en-el-departamento

OPS. (2020, septiembre). La Región de las Américas reporta la mayoría de las nuevas muertes por COVID-19 en todo el mundo-OPS/OMS | Organización Panamericana de la Salud. Recuperado 11 de octubre de 2020, de http://www.paho.org/es/noticias/1-9-2020-region-americas-reporta-mayoria-nuevas-muertes-porcovid-19-todo-mundo

Colombia. Presidencia de la República. (2020, marzo). Decreto 417 del 17 de marzo de 2020. Por el cual se declara un Estado de Emergencia Economica, Social y Ecologica en todo el territorio Nacional. Recuperado de https://coronaviruscolombia.gov.co/Covid19/docs/decretos/presidencia/51_Presidencia_Decreto_417.pd f

Ramírez Saavedra, B., Sarmiento, D., y Millán Rojas, E. (2016). Estrategia para afrontar la deserción universitaria desde las tecnologias de la información y las comunicaciones. Revista Científica, 1, 62.

https://doi.org/10.14483/udistrital.jour.RC.2016.24.a5

Stephany, B. G. A. (2019). Análisis de los factores de deserción estudiantil en el programa de pregrado enfermería de una universidad privada del municipio de Palmira, Colombia. 2019. AVFT - Archivos Venezolanos de Farmacología y Terapéutica, 3.

UFPSO. (2020). Medidas de prevención y protección: Suspensión de clases en el campus universitario.

Recuperado de https://ufpso.edu.co/ftp/pdf/documentos/2020/Comunicado_Coronavirus_enviar_080855_3505.pdf Attribución-NoCommercial 4.0 International

$(\mathrm{Cc}) \mathbf{B Y}$-NC 